\title{
Targeting the hypoxia pathway in malignant plasma cells by using 17-allylamino-17-demethoxygeldanamycin
}

\author{
Kinga A. Kocemba-Pilarczyk ${ }^{\bowtie}$, Barbara Ostrowska, Sonia Trojan, Ecce Aslan\#, Dorota Kusior, \\ Małgorzata Lasota, Claire Lenouvel and Joanna Dulińska-Litewka
}

Chair of Medical Biochemistry, Jagiellonian University Medical College, Kraków, Poland

\begin{abstract}
Multiple myeloma ( $\mathrm{MM})$ is characterized as a clonal expansion of malignant plasma cells in the bone marrow, which is often associated with pancytopenia and osteolytic bone disease. Interestingly, myeloma-infiltrated bone marrow is considered to be hypoxic, providing selection pressure for a developing tumour. Since HSP90 was shown to participate in stabilization of the subunit of the key transcription factor HIF-1, which controls the hypoxic response, the aim of this study was to investigate the influence of a HSP90 inhibitor 17-allylamino17-demethoxygeldanamycin (17-AAG), on MM cells cultured under low oxygenation conditions. We confirmed that 17-AAG inhibits hypoxic induction of the HIF-1 target genes in malignant plasma cells and demonstrate the concentration range of severe hypoxia-specific cytotoxicity. Next, we selected the malignant plasma cells under severe hypoxia/re-oxygenation culture conditions in the presence or absence of 17-AAG and subsequently, the cells which survived were further expanded and analyzed. Interestingly, we have noticed significant changes in the survival and the response to anti-MM drugs between the parental cell lines and those selected in cyclic severe hypoxia in the presence and absence of 17-AAG. Importantly, we also observed that the lack of oxygen itself, irrespectively of HIF-1 inhibition, is the main/pivotal factor driving the selection process in the experiments presented here.
\end{abstract}

Key words: Multiple myeloma, HIF-1, hypoxia, 17-AAG

Received: 11 August, 2017; revised: 28 November, 2017; accepted: 13 December, 2017; available on-line: 15 March, 2018

e-mail: kinga.kocemba@uj.edu.pl

\#Ecce Aslan was working on this project in frame of The International Federation of Medical Students' Associations (IFMSA) exchange program

Abbreviations: 17-AAG, 17-allylamino-17-demethoxygeldanamycin; BM, bone marrow; HIF-1 alpha, hypoxia-inducible factor 1 alpha; Hsp90, heat shock protein 90; MM, multiple myeloma; MMSC, multiple myeloma stem cells; MTT, methyl-thiazolyl-tertazolium; PHDs, prolyl hydroxylases; VHL, von Hippel-Lindau protein

\section{INTRODUCTION}

Multiple Myeloma (MM) is an incurable B-cell malignancy, described as malignant expansion of monoclonal plasma cells in the bone marrow (BM). Transformation of a normal plasma cell into aggressive myeloma is a multistep process which requires the accumulation of multiple genetic "hits". During disease progression, myeloma cells are closely dependent on the BM environment, indicating that interaction with the niche plays a crucial role in the development of this tumor (Palumbo \& Anderson, 2011). According to the cur- rent status of knowledge, MM shows a heterogeneous subclonal structure at diagnosis (Bianchi \& Ghobrial, 2014), which evolves further in parallel to differential response of subclones to micro-environmental pressure (Bolli et al., 2014).

In the cancerogenesis, one of the most important micro-environmental selection factors is hypoxia (Graeber et al., 1996). Although the presence of low oxygen pressure in normal (Levesque et al., 2007; Parmar et al., 2007; Levesque and Winkler, 2011) and MM-infiltrated mouse BM (Asosingh et al., 2005) was reported in several studies, the importance of hypoxia in the progression of MM has not yet been fully elucidated. Studies by Colla et al., Giatromanolaki et al., Martin et al. and Borsi et al. (Colla et al., 2010; Giatromanolaki et al., 2010; Martin et al., 2010; Borsi et al., 2014), on malignant plasma cells confirmed nuclear accumulation of HIF-1 (Hypoxia Inducible Factor-1), the key transcription factor for hypoxia response (stabilized in hypoxic conditions $<2 \%$ $\mathrm{O}_{2}$ ), which upregulates several genes to promote survival under low-oxygen conditions (Semenza, 2003). Interestingly, however, direct measurement of oxygen pressure in human BM, performed by Colla et al. did not prove occurrence of hypoxia. Thus, nuclear accumulation of HIF-1 observed in malignant plasma cells, in parallel to relatively high oxygen partial pressure reported in human MM-infiltrated BM by Colla and coworkers (above $50 \mathrm{mmHg}, 6.5 \% \mathrm{O}_{2}$ ), could be most probably explained as heterogeneity in the local oxygen distribution in the bone marrow, supporting the hypothesis of hypoxia niches (Hu et al., 2012). Alternatively, in malignant plasma cells, the nuclear HIF-1 accumulation could be hypoxia-independent, as reported by the Anderson laboratory, which demonstrated HIF-1 protein stabilization and activity in some MM patients under normoxic conditions (Zhang et al., 2009).

Several findings in solid tumors support the hypothesis that exposure to hypoxia and re-oxygenation provides a strong selection pressure contributing to the enrichment of cancer stem cells (Keith \& Simon, 2007; Li \& Rich, 2010). In MM, hypoxia was reported to induce immature phenotype of malignant cells and the acquisition of a quiescent state (Muz et al., 2014). Moreover, enhanced tumor initiation and increased drug resistance to bortezomib and carfilzomib was observed in the hypoxic myeloma cells (Muz et al., 2014). In addition, study by Azab et al. revealed that hypoxia activates EMT (Epithelial Mesenchymal Transition) - related proteins and induces metastasis of malignant plasma cells by stimulating the migration and homing to the new BM niches (Azab et al., 2012). Thus, the data published so far suggest that targeting the hypoxic myeloma cells may serve as a promising therapeutic approach. 


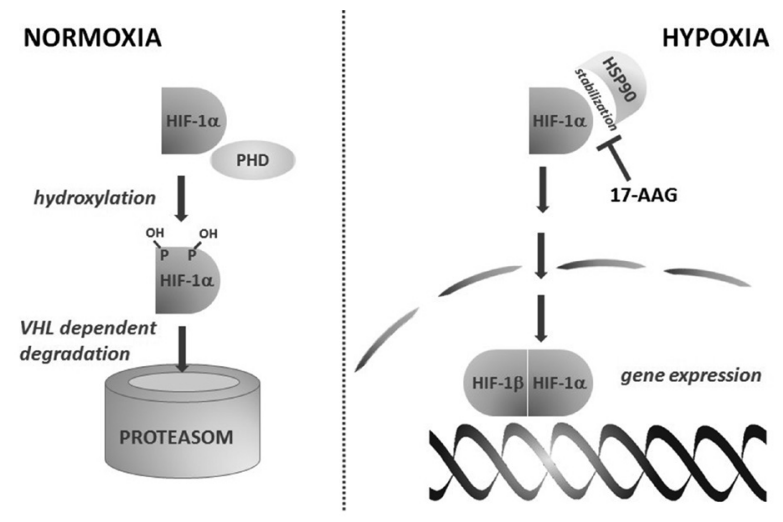

Scheme 1. The regulation of HIF-1 alpha level/stability.

Under normoxic conditions, HIF-1 alpha is hydroxylated by specific prolyl hydroxylases (PHDs) in a reaction that requires $\mathrm{O}_{2}$, allowing HIF-1 alpha binding with von Hippel-Lindau (VHL) protein to enable its ubiquitination and subsequent degradation by the proteasome machinery. Under hypoxic conditions, PHD is inactive and hydroxylation following subsequent polyubiquitination cannot take place. Moreover, HIF-1 alpha stabilization/action is further enhanced by interactions with HSP90 which protects HIF-1 alpha subunit against VHL-independent proteasomal degradation. HIF1 alpha translocates to the nucleus and heterodimerizes with the HIF-1 beta subunit to regulate gene expression.

According to current knowledge, besides the classical oxygen-dependent regulators of HIF-1 activity, the chaperone heat shock protein 90 (HSP90) was shown to stabilize HIF-1 alpha subunit in oxygen-independent manner, protecting it from proteasomal degradation (Isaacs et al., 2002; Koh and Powis, 2012). Thus, according to Scheme 1, application of 17-allylamino-17-demethoxygeldanamycin (17-AAG) - a potent inhibitor of HSP90 chaperoning activity - may influence the MM cells' response to hypoxic conditions, especially in the light of the work by Mitsiades and coworkers (Mitsiades et al., 2006), who demonstrated suppression of basal, normoxic HIF-1 alpha transcriptional activity in MM cells treated with 17-AAG under normoxic conditions. Considering pros and cons of interference in hypoxic signalling, one may speculate whether such disturbance/reprogramming of the cell's response to hypoxic condition, resulting from impairment of HIF-1 alpha stabilization by HSP90, may serve as an additional driving force in the context of cell stemness and/or selection of more resistant MM clones/subclones.

In this paper we reported the influence of $17-A A G$ on MM cells cultured under low oxygenation conditions, revealing the increased compound toxicity against malignant plasma cells cultured under chronic and cyclic severe hypoxia $\left(<0.01 \% \mathrm{O}_{2}\right)$ in comparison to normoxic MM cells. In line with this data, we show for the first time that 17-AAG can block induction of the HIF-1 target genes in malignant plasma cells cultured in the hypoxic environment. Moreover, we performed the functional comparison of cells selected in the presence and absence of 17-AAG demonstrating changes acquired during the selection process under cyclic severe hypoxia.

\section{MATERIALS AND METHODS}

Materials. 17-AAG was supplied by Sigma-Aldrich, reconstituted in sterile DMSO (Sigma Aldrich) and used at the micromolar concentration range. Doxorubicin was purchased from Sigma-Aldrich, reconstituted in sterile water (Cytogen) and used at the nanomolar concentration range. Bortezomib (Santa Cruz Biotechnology, Inc.) was supplied as a lyophilized powder, reconstituted in sterile DMSO (Sigma Aldrich) and used at the nanomolar concentration range. $1 \mathrm{~kb}$ DNA ladder for agarose gel electrophoresis was supplied by Cytogen (Solis Biodyne). Protein ladder was supplied by Thermo Fisher Scientific.

Cell culture. L363 and RPMI 8226 (obtained from German Collection of Microorganisms and Cell Cultures, DSMZ) were cultured in the RPMI1640 medium (Gibco, Life Technologies) containing 10\% Heat Inactivated Fetal Bovine Serum (FBS) (Gibco, Life Technologies), 100 units $/ \mathrm{ml}$ penicillin (Sigma Aldrich), and $100 \mu \mathrm{g} / \mathrm{ml}$ streptomycin (Sigma Aldrich). Cells were cultured either under normal conditions $\left(37^{\circ} \mathrm{C}\right.$ and $5 \% \mathrm{CO}_{2}$ equilibrated with atmospheric $\mathrm{O}_{2}$ that contained $21 \% \mathrm{O}_{2}$ ) (hereafter referred to as normoxia) or in the Modular Incubator Chamber (Billups-Rothenberg, Inc., 5\% $\mathrm{CO}_{2}, 95 \% \quad \mathrm{~N}_{2}$ ) that was placed at $37^{\circ} \mathrm{C}$ (hereafter referred to as severe hypoxia). To obtain the severe hypoxic conditions, the gas mixture of $5 \% \mathrm{CO}_{2}$ and $95 \% \mathrm{~N}_{2}$ was flushed through the Modular Incubator Chamber at the flow rate of 25 liters per minute for 10 minutes. Next, the chamber was returned to conventional incubator for 1 hour to allow culture media to de-gas and then the flush at the flow rate of 25 liters per minute was repeated for another 10 minutes. According to the literature (Wu et al., 2011) and the manufacturer instructions (Billups-Rothenberg), 10 minute flushing at the indicated flow rate completely purges the Modular Incubator Chamber, removing most if not all oxygen present in the chamber and in the culture media. Thus, the conditions obtained in the Modular Incubator Chamber were referred in accordance to literature (Papandreou et al., 2005; Achison et al., 2003) as severe hypoxia $\left(<0.01 \% \mathrm{O}_{2}\right)$.

RT-PCR. Total RNA was isolated using GenElute ${ }^{\mathrm{TM}}$ Mammalian Total RNA Miniprep Kit (Sigma-Aldrich) according to the manufacturer's instructions. The quantity of total RNA was measured using a NanoDrop ND-1000 Spectrophotometer (NanoDrop Technologies, Wilmington, DE). cDNA synthesis was performed using oligo (dT) 15 primer and GoScript Transcriptase according to the manufacturer's instructions (Promega GmbH, Germany). The PCR mixture contained: $1.5 \mu \mathrm{l}$ of $\mathrm{cDNA}, 0.2$ $\mu \mathrm{l}$ of each $10 \mu \mathrm{M}$ primers, $10 \mu \mathrm{l}$ of Color OptiTaq PCR Master Mix (2x) (EURx, Poland) and $10 \mu \mathrm{l}$ of nuclease free deionized water. Primers used were: SLC2A1 (Solute carrier family 2, facilitated glucose transporter member 1) forward (5-T'TGGCTCCGGTATCGTCAAC-3), SL2CA1 reverse (5-GGTCCGGCCTTTAGTCTCAG-3), PFKFB4 (6-Phosphofructo-2-Kinase/Fructose-2,6-Biphosphatase 4) forward (5-GGGATGGCGTCCCCACGGG-3), PFKFB4 reverse (5-CGCTCTCCGTTCTCGGGTG-3), LDHA (Lactate Dehydrogenase A) forward (5-CTGTTCCACTTAAGGCCCCTC-3), LDHA reverse (5-CCAGCCT'T'TCCCCCAT'TAGG-3), CAIX (Carbonic Anhydrase 9) forward (5-TACAGCTGAACTTCCGAGCG-3), CAIX reverse (5-CTAGGCTCCAGTCTCGGCTA-3), HPRT1 (Hypoxanthine-Guanine Phosphoribosyltransferase 1) forward (5-TGGCGTCGTGATTAGTGATG-3), HPRT1 reverse (5-TATCCAACACTTCGTGGGGT-3). All primers were manufactured by Sigma-Aldrich. The PCR conditions for all of the analyzed genes were as following: denaturing at $95^{\circ} \mathrm{C}$ for $5 \mathrm{~min}$ utes, followed by 30 cycles of 30 seconds at $95^{\circ} \mathrm{C}, 30$ seconds at $58^{\circ} \mathrm{C}$ and 30 seconds at $72^{\circ} \mathrm{C}$. The reaction was completed for 10 minutes at $72^{\circ} \mathrm{C}$. 
Western Blot. Multiple myeloma cells were lysed directly in the sample buffer and harvested protein was separated by SDS $/ 10 \%$ PAGE, and blotted. Primary rabbit anti-HIF-1 antibody (\#3716, Cell Signalling) was detected by anti-rabbit IgG, HRP-linked Antibody (\#7074, Cell Signalling), followed by visualization using ECL ${ }^{\mathrm{TM}}$ Western Blotting Detection Reagents (GE, Healthcare). Primary mouse monoclonal anti- $\beta$-actin antibody (Clone AC-15, Sigma Aldrich) was detected by anti-mouse IgG, HRP-linked Antibody (\#7076, Cell Signalling), followed by visualization using ECL Western Blotting Detection Reagents (GE, Healthcare). Digital images were taken with Bio-Rad ChemiDoc ${ }^{\mathrm{TM}}$ XRS+ System (Bio-Rad).

MTT (Methyl-Thiazolyl-Tertazolium) assay adjusted for cells cultured in suspension. The MT'T assay was used as a survival assay and cytotoxicity assay for doxorubicin and bortezomib. Briefly, for survival assay, the myeloma cells $\left(2 \times 10^{4}\right.$ cells/well $)$ were seeded into 96-well plates in $200 \mu \mathrm{l}$ of RPMI1640 culture medium without phenol red (supplemented with 100 units $/ \mathrm{ml}$ penicillin and $100 \mu \mathrm{g} / \mathrm{ml}$ streptomycin) and cultured for 5 days with varying concentrations of FBS $(0.5 \%, 1 \%, 2.5 \%$ and $5 \%)$. For cytotoxicity assay, the myeloma cells $\left(4 \times 10^{4}\right.$ cells $/$ well $)$ were seeded into 96-well plates and cultured with varying concentrations of doxorubicin and bortezomib in $200 \mu \mathrm{l}$ of RPMI1640 culture medium without phenol red (supplemented with 100 units/ml penicillin and $100 \mu \mathrm{g} /$ $\mathrm{ml}$ streptomycin and 5\% FBS) for $48 \mathrm{~h}$. For $17-\mathrm{AAG}$ cytotoxicity assessment, the myeloma cells $\left(3 \times 10^{4}\right.$ cells/well) were seeded into 96-well plates and cultured with varying concentrations of 17-AAG in 200 $\mu \mathrm{l}$ of RPMI1640 culture medium without phenol red (supplemented with antibiotics and 5\% FBS) for $24 \mathrm{~h}$. Next, the cells were subjected to severe hypoxia for additional $72 \mathrm{~h}$. In order to detect the living cells, after the incubation period, $10 \mu \mathrm{l}$ of the dye (3, [4,5-dimethylthiazol-2-yl-] diphenyltetrazolium bromide, 5 $\mathrm{mg} / \mathrm{ml}$ ) (Sigma Aldrich) was added to each well and the plate was left at $37^{\circ} \mathrm{C}$ for $3 \mathrm{~h}$. After that incubation period, the cells were lysed by adding $100 \mu \mathrm{l}$ of the lysis buffer $(10 \%$ SDS in $0.01 \mathrm{M} \mathrm{HCl})$ and left for another $24 \mathrm{~h}$ at $37^{\circ} \mathrm{C}$ to complete the lysis. The viable cells were determined by measuring the optical density at $570 \mathrm{~nm}$, using Synergy_HT plate reader (Biotek Instruments, USA).

\section{RESULTS}

\section{Response of the malignant plasma cells to severe hypoxia}

Initially, to validate our experimental setup, we determined the influence of severe hypoxia on malignant plasma cells. Our Western blot analysis revealed the expected response to low oxygen environment, confirmed by stabilization of the HIF-1 alpha subunit (Fig. 1, upper panel). The characteristic $120 \mathrm{kDa}$ alfa subunit band was detected only in cells subjected to severe hypoxia, whereas in normoxic cells only the band of $100 \mathrm{kDa}$ was visible on the exposed membrane, which most probably matches the degradation or cleavage product of HIF-1 alpha. To analyze the response at the mRNA level, we checked expression of genes (SLC2A1, PFKFB4, LDHA, CAIX) previously confirmed in the literature as the HIF-1 target genes (Harris, 2002; Minchenko et al., 2004), whose upregulation in low oxygen environment was published to occur in malignant plasma cells (Kocemba et al., 2013). In the L363 cell line, we confirmed the hypoxic induction of all analyzed genes by using the semi-quantitative RT-PCR, whereas in the RPMI 8226 cell line, the clear hypoxic induction was visible only in the case of CAIX and PFKFB4. Contrary to the L363 cell line, initial expression of LDHA and SLC2A1 in the RPMI 8226 cells was already high under normoxic conditions and was not further induced in severe hypoxia (Fig. 1 lower panel).

\section{Survival of the malignant plasma cells under severe hypoxic conditions in the presence and absence of the HIF-1 inhibitor}

In our study, we focused on 17-AAG, the HSP90 inhibitor, with confirmed anti-MM cytotoxicity (Mitsiades et al., 2006; Jurczyszyn et al., 2014). Although 17-AAG has been already reported as a compound inhibiting the HIF-1 pathway (Isaacs et al., 2002; Mitsiades et al., 2006), thus far there has been lack of data showing the hypoxia specific effect of 17-AAG on survival of malignant plasma cells in a low oxygen environment. To investigate the hypoxia specific effect of 17-AAG on malignant plasma cells, we analysed the viability of cells cultured for $72 \mathrm{~h}$ under hypoxic and normoxic conditions in the presence and absence of this inhibitor, at the concentration range of $0.015-0.25 \mu \mathrm{M}$ (Fig. 2A). Upon indicated time points, the number of living cells was assessed by the MT'T assay adjusted for cells cultured in suspension. Interestingly, for both cell lines we found concentrations of 17-AAG that influenced the cells cultured under severe hypoxia more significantly than those cultured under normoxic conditions (Fig. 2A). In order to determine if 17-AAG can influence the HIF-1 pathway in malignant plasma cells, we compared induction of the HIF-1 target genes in the cells cultured for $24 \mathrm{~h}$ under severe hypoxic conditions in the presence and absence of 17-AAG. As shown in Fig. 2B, 17-AAG significantly attenuated the
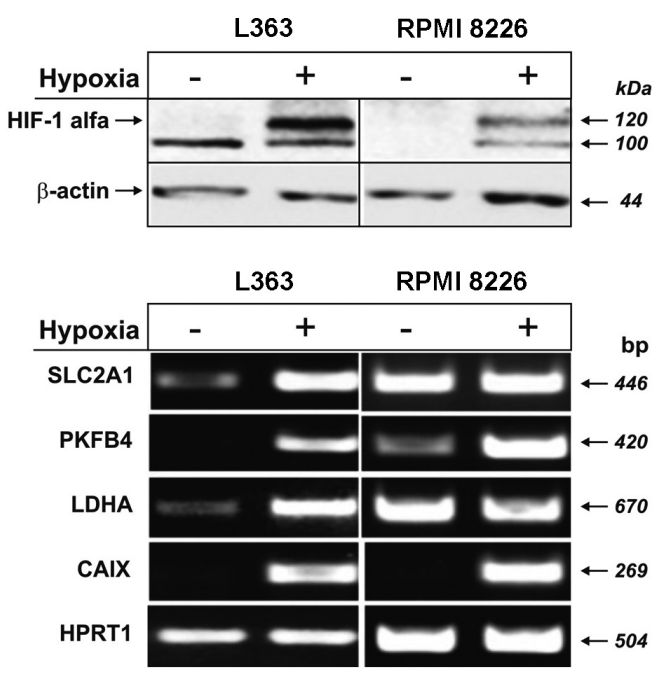

Figure 1. Upper panel; HIF-1 alpha accumulation in L363 and RPMI 8226 MM cell lines.

L363 and RPMI 8226 in response to hypoxia. MM cell lines were cultured under normoxic (-) or severe hypoxic (+) conditions for $24 \mathrm{~h}$. HIF-1 alpha was detected using Western blot. $\beta$-actin is shown as an internal control for equal protein loading.

Lower panel; Induction of hypoxia target genes in MM cell lines. The expression of HIF-1 target genes was determined by RT-PCR following $24 \mathrm{~h}$ exposure to normoxic (-) or severe hypoxic (+) conditions. HPRT1 is shown as an internal control for equal amount of CDNA. 
A

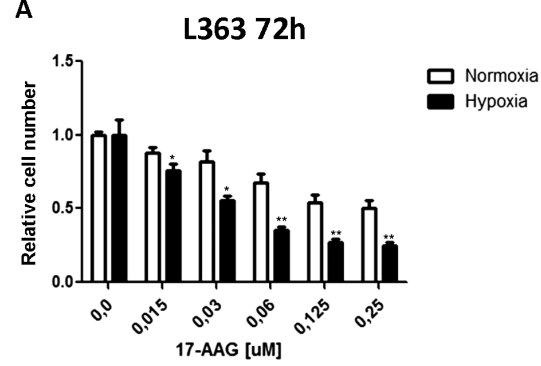

B

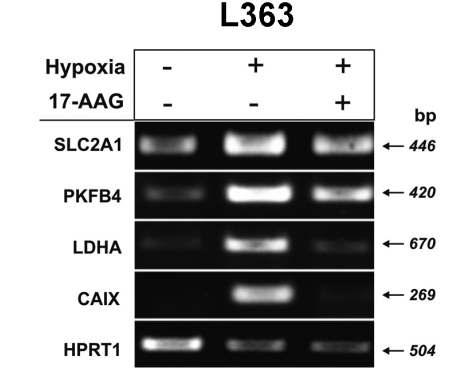

C

L363

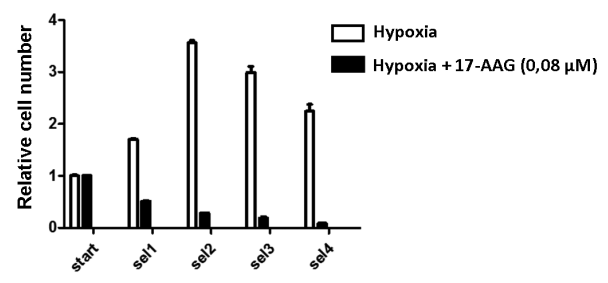

RPMI $822672 \mathrm{~h}$

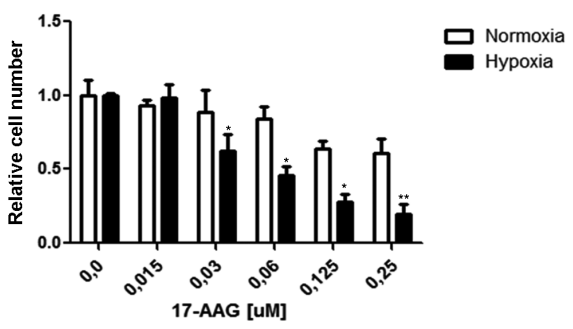

RPMI 8226

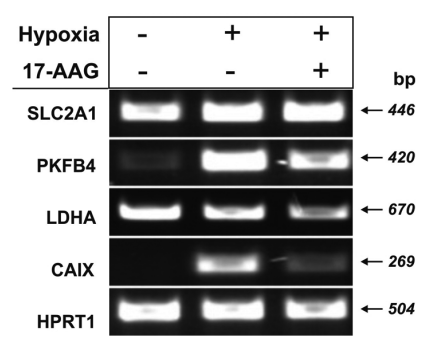

RPMI 8226

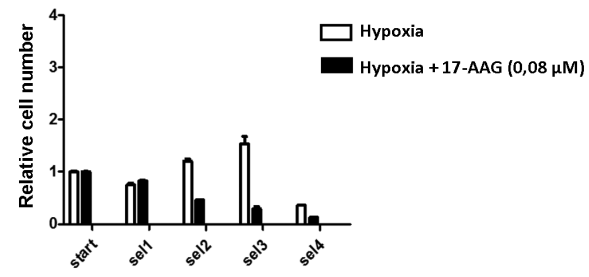

Figure 2. (A) Anti-MM activity of 17-allylamino-17-demethoxygeldanamycin (17-AAG) under chronic severe hypoxic conditions. MM RPMI 8226 and L363 cell lines $\left(3 \times 10^{4}\right.$ cells/well) were cultured in normoxia and continuous severe hypoxia in the presence or absence of 17-AAG $(0.015-0.25 \mu \mathrm{M})$. After $72 \mathrm{~h}$, the number of living cells was determined by MTT assay. The absorbance of cells under control conditions (without 17-AAG) was normalized to 1 and subsequently all results were normalized to the control values (untreated cells). The mean \pm S.D. of a representative experiment performed in triplicate is shown. Student's $t$-test was used for statistical data comparison between normoxic and severe hypoxic conditions. *indicates $p$ value $<0.05$, **indicates $p$ value $<0.01$, ***indicates $p$ value $<0.001$, by the Student's $t$-test.

(B) Hsp90 inhibition targets HIF-1 signaling in MM.

The expression of HIF-1 target gene, SLC2A1, PFKFB4, LDHA, CAIX, and HPRT1 as the housekeeping control, was determined by RT-PCR following $24 \mathrm{~h}$ exposure to normoxia (-), severe hypoxia (+) and severe hypoxia in the presence of 17-AAG (1.25 $\mu \mathrm{M})$.

(C) Anti-MM activity of 17-allylamino-17-demethoxygeldanamycin (17-AAG) under cyclic severe hypoxic conditions.

MM L363 and RPMI 8226 cell lines were cultured in cycling severe hypoxia in the presence and absence of 17-AAG (0.08 $\mu M)$. Upon indicated time points (start, sel1, sel2, sel3, sel4) the number of living cells was determined by MTT assay. The absorbance of cells at day 0 was normalized to 1 and subsequently all of the results were normalized to day 0 . Start - day 0 , Sel 1 - selection point $1 ; 24 \mathrm{~h}$ normoxia, $24 \mathrm{~h}$ severe hypoxia, Sel2 - selection point $2 ; 24 \mathrm{~h}$ normoxia, $24 \mathrm{~h}$ severe hypoxia, $2 \mathrm{~h}$ re-oxygenation, $16 \mathrm{~h}$ severe hypoxia, Sel $3-$ selection point 3; $24 \mathrm{~h}$ normoxia, $24 \mathrm{~h}$ severe hypoxia, $2 \mathrm{~h}$ re-oxygenation, $16 \mathrm{~h}$ severe hypoxia, $8 \mathrm{~h}$ re-oxygenation, $24 \mathrm{~h}$ severe hypoxia, Sel4 - selection point 4; $24 \mathrm{~h}$ normoxia, $24 \mathrm{~h}$ severe hypoxia, $2 \mathrm{~h}$ re-oxygenation, $16 \mathrm{~h}$ severe hypoxia, $8 \mathrm{~h}$ re-oxygenation, $24 \mathrm{~h}$ severe hypoxia, 2 h re-oxygenation, 72 h severe hypoxia.

severe hypoxia-induced expression of HIF-1 target genes in both cell lines. Thus, based on the data obtained we conclude that survival of malignant plasma cells under severe hypoxic conditions is influenced by inhibition of HSP90, which has been shown to affect the HIF-1 pathway in MM.

\section{Selection of the malignant plasma cells in cycling anoxia with and without the HIF-1 inhibitor}

To investigate the influence of cyclic severe hypoxia on malignant plasma cells, we carried cell culture under the severe hypoxia/re-oxygenation cycles. The goal of this experiment was to select the population able to survive under the severe hypoxic conditions. Of note, we observed that cycling severe hypoxia had a cell line specific influence on malignant plasma cells. Under the control conditions, in the absence of $17-\mathrm{AAG}$, when the short severe hypoxia re-oxygenation time points were applied, the cells continue to divide (Fig. 2C). Nevertheless, upon the last selection point the number of cells significantly declined in both cell lines. Moreover, the growth of cells cultured with 17-AAG $(0.08 \mu \mathrm{M})$ was on the decline even during initial severe hypoxia re-oxygenation time points. Particularly, in the case of the RPMI 8226 cell line we initially observed growth inhibition only, whilst in the case of L363 an immediate drop in cell number was apparent (Fig. 2C). Of note, upon the last selection point in both cell lines in the presence of 17-AAG $(0.08 \mu \mathrm{M})$ only single living cells were detected, confirming much stronger selection pressure under HIF-1 inhibitory conditions. Since it is highly possible that hypoxic pressure can select for a particular subclone and/or cancer stem cells of a particular subclone, the remaining cells were further expanded and the newly selected cell lines were subjected to a functional analysis. 
A
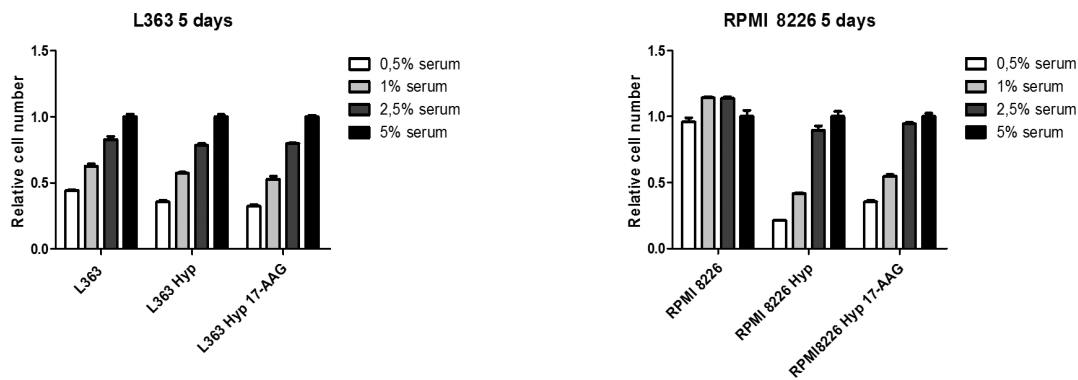

B

L363 48h

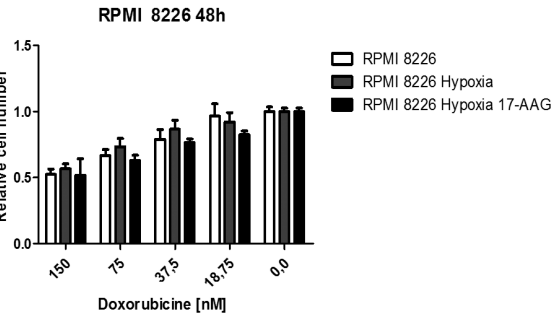

L363 48h
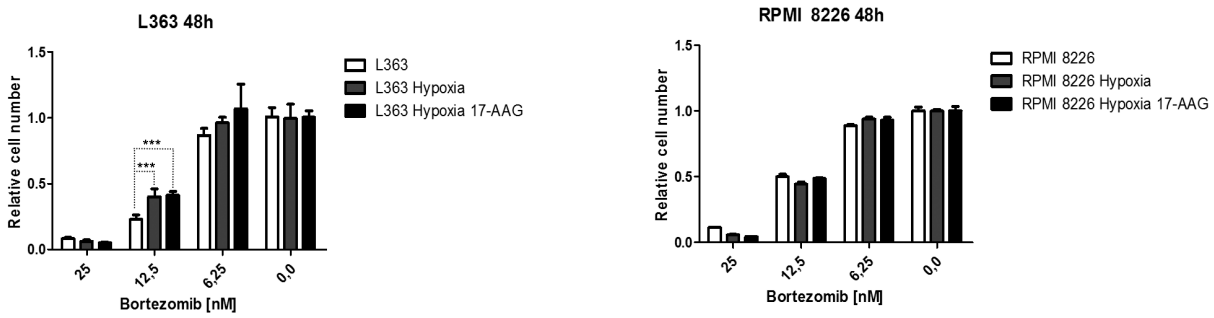

Figure 3. (A) Survival assay of malignant plasma cells selected under severe hypoxic conditions in the presence and absence of 17-allylamino-17-demethoxygeldanamycin (17-AAG).

Multiple myeloma cells $\left(2 \times 10^{4}\right.$ cells/well) were seeded into 96 -well plates and cultured with varying concentrations $(0.5 \%, 1 \%, 2.5 \%, 5 \%)$ of serum for 5 days. The number of living cells was determined by MTT assay. The absorbance of cells under control conditions $(5 \%$ serum) was normalized to 1 and subsequently the results obtained with different serum concentrations were normalized to the control conditions (5\% serum FBS). The response to indicated serum concentration was performed for parental cell lines (L363, RPMI 8226), cells selected under severe hypoxic conditions (L363 Hyp, RPMI 8226 Hyp) and the cells selected under severe hypoxic conditions in the presence of $0.08 \mu \mathrm{M}$ 17-AAG (L363 Hyp17-AAG, RPMI 8226 Hyp 17-AAG). The mean \pm S.D. of a representative experiment performed in triplicate is shown. Student's $t$-test was used for statistical data comparison. ${ }^{*}$ indicates $p$ value $<0.05$, **indicates $p$ value $<0.01$, ***indicates $p$ value $<0.001$, by the Student's $t$-test.

(B) Effect of doxorubicin and bortezomib on malignant plasma cells selected under severe hypoxic conditions in the presence and absence of 17-allylamino-17-demethoxygeldanamycin (17-AAG).

Multiple myeloma cells $\left(4 \times 10^{4}\right.$ cells/well) were seeded into 96-well plates and cultured with varying concentrations of doxorubicin (18.75-150 nM) and bortezomib (6.25-25 nM) for $48 \mathrm{~h}$. The number of living cells was determined by MTT assay. The absorbance of cells under control conditions was normalized to 1 and subsequently all the results were normalized to the control conditions (without chemotherapeutics). The response to chemotherapeutics was carried out for parental cell lines (L363, RPMI 8226), cells selected under severe hypoxic conditions (L363 Hypoxia, RPMI 8226 Hypoxia) and the cells selected under severe hypoxic conditions in the presence of 17-AAG (L363 Hypoxia 17-AAG, RPMI 8226 Hypoxia 17-AAG) $(0.08 \mu \mathrm{M})$. The mean \pm S.D. of a representative experiment performed in triplicate is shown. Student's $t$-test was used for statistical data comparison. *indicates $p$ value $<0.05$, **indicates $p$ value $<0.01$, ***indicates $p$ value $<0.001$, by the Student's $t$-test.

Functional analysis of the malignant plasma cells selected under severe hypoxia/re-oxygenation culture conditions with and without HIF-1 inhibition

Functional analysis of cells selected under severe hypoxic conditions comprised studying response to different serum concentrations and the response to chemotherapeutics commonly used in the treatment of MM. First, we compared the influence of decreasing serum concentrations on L363 and RPMI 8226 cells selected under severe hypoxic conditions in the presence and absence of the HSP90 inhibitor. As shown in Figure 3A, the selected cells of RPMI 8226 responded differently to the decreasing serum content in the culture medium. Interestingly, however, our survival assay revealed that the RPMI 8226 cells selected under severe hypoxia with and without 17-AAG were more dependent on growth factors in comparison to the parental cells (Fig. 3A). Contrary, in the L363 cells we did not observe any relevant differences under varying growth conditions (Fig. 3A) among the analyzed parental and selected cell lines. Next, we analyzed the response of malignant plasma cells selected under different conditions, to the chemotherapeutics commonly used in advanced MM (Palumbo et al., 2008). We analyzed the response to bortezomib (6.25 nM to $25 \mathrm{nM}$ ) and doxorubicine (18.75 $\mathrm{nM}$ to $150 \mathrm{nM})$. As shown in Fig. 3B, in the L363 cells selected under hypoxic conditions with and without $17-\mathrm{AAG}$, repeatedly demonstrated lower sensitivity to certain concentrations of doxorubicin (75 nM, $150 \mathrm{nM}$ ) and bortezomib (12.5 
$\mathrm{nM}$ ), whereas in the RPMI 8226 cell line we did not observe any reproducible changes between the parental cell line and the cells selected under severe hypoxic conditions in response to the analyzed chemotherapeutics (Fig. 3B).

\section{DISCUSSION}

Previous research analysing the behaviour of cells in low oxygen environment pointed to HIF-1 as a crucial transcription factor mediating cellular response to hypoxia (Semenza, 2003; 2007). Study by Semenza et al. revealed that the HIF-1 transcription factor is responsible for adaptation to low oxygen environment by increasing the glucose transport and its breakdown, allowing the adequate ATP production despite the reduced efficiency of anaerobic metabolism, among others (Semenza, 2002; 2003). We have previously demonstrated that hypoxia enhances the angiogenic potential of malignant plasma cells contributing directly to MM-induced angiogenesis (Kocemba et al., 2013), the process crucial for expansion of malignant plasma cells in the bone marrow (Giulani et al., 2011). Although anti-angiogenic therapy was enthusiastically admitted in the cancer field, the angiogenesis inhibitors fail to produce sustained clinical response in many patients and resistance to anti-angiogenic agents frequently develops (Vasudev \& Reynolds, 2014). The disappointing performance of the anti-angiogenic agents may very well be the consequence of hypoxia and nutrient limitations occurring after devascularisation. These alterations force the acquisition of mutations in cells which may lead to selection of more aggressive clones able to survive beyond the original limitations (Ebos et al., 2009; Loges et al., 2009; Paez-Ribes et al., 2009; Mcintyre \& Harris, 2015). In order to find a potential solution, researchers have tested therapeutic approaches targeting the hypoxic tumour compartment to prevent the survival and selection of cells in low oxygen micro-environment (Xia et al., 2012). In this study we revealed that 17-allylamino-17-demethoxygeldanamycin, a heat shock protein 90 inhibitor, selectively targets the severe hypoxic malignant plasma cells, in the range of concentrations tested. Of note, to the best of our knowledge, this is the first report showing that 17-AAG can block induction of HIF-1 target genes in malignant plasma cells under hypoxic conditions. Although the influence of 17 AAG on the HIF-1 pathway was already reported in malignant plasma cells by Mitsiades and coworkers (Mitsiades et al., 2006), these authors revealed the impact of 17-AAG only at the basal, normoxic HIF-1 transcriptional activity.

Although 17-AAG seems to be toxic for malignant plasma cells cultured in low oxygen environment, we cannot exclude that by acting on the cells in the hypoxic/anoxic niches the selection pressure is further enhanced, namely the cells which are able to survive under severe hypoxic conditions without active HIF-1 transcription factor are subjected to double stress - the lack of oxygen and incapability for metabolic reprogramming initiated by the HIF-1 transcription factor. Moreover, HIF-1 attenuation may contribute to an increase in the oxidative stress (Zhao et al., 2014), leading to higher rates of oxidative damage and the acquisition of new mutations in the cells. Thus, there is a possibility that HIF-1 inhibitors may select for more aggressive clones, with additional mutations in genes important for tumour metabolism. On the other hand, it has been reported that mouse lymphoma and Acute Myeloid Leukemia (AML) cancer stem cells (CSCs) were selectively sensitive to low concentration of 17-AAG (Newman et al., 2012).
That effect was the consequence of the loss of HIF-1 function, which is crucial for the maintenance of both, mouse lymphoma and AML CSCs. To further validate the influence of $17-\mathrm{AAG}$ on MM stem cells (MMSC) would be definitely of high importance, nevertheless, the most significant problem so far is to isolate the population of MMSC in order to study and definitely describe their unique biology (Kellner et al., 2013). As a consequence, the interest of current studies in the field of MM focuses on clonal heterogeneity and related differential response to targeted therapies (Keats et al., 2012; Bolli et al., 2014; Lohr et al., 2014; Melchor et al., 2014). Although the next generation sequencing method has been already applied in MM patients to track the alterations in clonal structure induced by particular treatment (Bolli et al., 2014), according to our knowledge, no study so far has implemented this type of analysis in a model of hypoxia and/or anoxia. For our analysis we chose two MM cell lines in which analysis of karyotypes' structure confirmed clonal heterogeneity. In L363 cell line two main structural variants of karyotype were determined, whereas in RPMI 8226 cells a significant karyotypic heterogeneity was reported. The main structural variant of karyotype in the RPMI 8226 cells was detected only in $42 \%$ of cells, whereas the remaining cells contained non-clonal chromosome rearrangements (Turilova et al., 2012). Functional studies of hypoxia/anoxia selected cells, which we propose in this paper, may serve as an initial step in studying the changes in malignant plasma cells selected in low oxygen environment, and depending on the results, they may give the basis for more advanced investigation. In our experiment, the number of cells which survived the anoxia/re-oxygenation culture conditions in the presence of $17-\mathrm{AAG}$ was much lower in comparison to anoxia/re-oxygenation alone, showing the much stronger selection pressure in the presence of the compound inhibiting HIF-1 pathway. Interestingly, our data revealed that RPMI 8226 cells selected in cyclic severe hypoxia are more dependent on growth factors in comparison to the parental line. Of note, higher growth factor sensitivity was observed in both RPMI 8226 selected cell lines, obtained either by severe hypoxia/re-oxygenation selection alone or severe hypoxia/ re-oxygenation selection combined with 17-AAG application, which suggests that the altered response to serum-derived growth factors was induced exclusively by the severe hypoxic environment. According to literature, RPMI 8226 cells show lower cytokine sensitivity in comparison to L363 cells in an experimental culture, and our data obtained for parental cell lines seems to be consentient with this observation (Zlei et al., 2007). In contrast, the high growth factor sensitivity observed exclusively in RPMI 8226 selected cells may reflect selection of a particular subclone, highly sensitive to external growth factors.

As for the alterations in the L363 cells selected in cyclic severe hypoxia, we demonstrated inferior sensitivity to doxorubicin and bortezomib for both L363 selected cell lines, obtained either by severe hypoxia/re-oxygenation selection alone or severe hypoxia/re-oxygenation selection combined with $17-\mathrm{AAG}$ application. Of note, the decreased sensitivity to bortezomib and doxorubicin may very well be the consequence of the acquired alterations in selected cells which interfere with the mechanism of actions for these chemotherapeutics. Briefly, bortezomib, formerly known as Velcade, PS-341, is a boronic acid dipeptide, which reversibly and highly selectively inhibits the catalytic site of the 26S proteasome, an enzyme complex that plays a key role in degradation 
of ubiquitylated, abnormal or misfolded proteins (Adams et al., 2004). The anti-Multiple Myeloma action of bortezomib is related to inhibition of NF- $x \mathrm{~B}$ (Nuclear Factor kappa B) signalling (Hideshima et al., 2001), through prevention of $\mathrm{I} x \mathrm{~B} \alpha$ degradation and triggering of the unfolded protein response (UPR) (Obeng et al., 2006). Interestingly, unfolded protein response is also triggered by severe hypoxic conditions with subsequent transcriptional expression increase of ATF4 (Activating transcription factor 4) transcription factor activating genes that promote restoration of normal ER (Endoplasmic Reticulum) function and survival under hypoxia (Rzymski et al., 2010). Moreover, ATF4 also plays a crucial role in resistance to bortezomib by the induction of pro-survival pathways, such as autophagy, that can relieve the protein overload in bortezomib treated cells (Rzymski et al., 2010). Thus, it can be hypothesize that the cells which survived the severe hypoxic conditions have a higher basal or UPR induced expression level of ATF4, which eventually may result in lower sensitivity to proteasome inhibitors. As for doxorubicin, there are two proposed mechanisms of its ant-cancer activities; intercalation into DNA and disruption of topoisomerase-II-mediated DNA repair and generation of free radicals leading to oxidative stress damaging all cellular components (Gewirtz et al., 1999). The response to reactive oxygen species (ROS) may be modulated by an enzyme capable of deactivating the free radicals, such as glutathione peroxidase, catalase, and superoxide dismutase (Liou et al., 2010). As excessive ROS production is well documented during a severe hypoxia/reoxygenation process (Granger et al., 2015), therefore it is possible that the selected cells have higher expression level or activity of an enzyme responsible for free radicals' deactivation and as a consequence they may show lower sensitivity to doxorubicin.

Although it has been known that HIF-1 can directly induce drug resistance by several independent mechanisms (Rohwer \& Cramer, 2011), in our study we have shown that just severe hypoxic selection itself can trigger the direct chemotherapeutics' resistance in malignant plasma cells which may results from the acquisition of molecular alterations in the selected cells which interfere with the bortezomib and doxorubicin mechanisms of action. Importantly, the fact that we again observed the same phenomenon in the cells selected with and without 17-AAG, derived from the same parental cell line, suggests that the low oxygen environment served as a major selection factor in our experimental setup.

In fact, the observed functional changes can very well be the consequence of pre-existing subclonal structure of the analyzed cell lines and severe hypoxia - induced selection of the clones with distinct genetic profile. Indeed, by the use of a single cell transcriptomics analysis a study by Mitra and coworkers (Mitra et al., 2014) identified a subclonal structure within Human Myeloma Cell Lines (HMCLs) subjected to bortezomib treatment. Moreover, significant genetic diversity at subclonal levels has been proved as a driving force in the evolution of MM (Keats et al., 2012; Lohr et al., 2014; Melchor et al., 2014). Nevertheless, in relation to severe hypoxia, more advanced studies would be required to answer the intriguing question if severe hypoxia-induced selection process is in any way influenced by subclonal structure of the analyzed cell lines. This type of research seems to be highly rational since hypoxia is one of the strongest micro-environmental selection factors (Graeber et al., 1996), whereas most MM cases demonstrate a complex subclonal structure (Bolli et al., 2014). Alternatively, in addition to hypoxia induced subclonal selection, the observed changes can be the consequence of severe hypoxia - triggered long term epigenetic alterations in the selected cells. Interestingly, recently published studies confirmed that low oxygen environment induces changes in the histone modifications and DNA methylation (Lu et al., 2011; Tsai et al., 2014; Thienpont et al., 2016) leading in consequence to a hypoxia-adapted phenotype which can be maintained in the absence of HIF-1 (Watson et al., 2010; Thienpont et al., 2016). Thus, the functional changes observed in severe hypoxia selected MM cells can be in fact the consequence of both, selection of a particular subclone with additional severe hypoxiatriggered new epigenetic pattern.

In conclusion, our data show that the selection in low oxygen environment, as expected, induces functional changes in malignant plasma cells. Of note, the enhancement of selection pressure by the addition of HIF-1 inhibiting compound did not further augment the aggressiveness of selected cells, pointing to 17-AAG as a potential anti-MM agent with severe hypoxia specific cytotoxicity. Similarities observed in cells selected by severe hypoxic condition alone, as well as by severe hypoxia combined with HIF-1 inhibiting compound, seem to indicate that the lack of oxygen itself is the main/pivotal factor driving the selection process. Definitely, it would be very interesting to apply the advanced techniques as e.g. massive parallel sequencing, to answer the question if clonal evolution may contribute in any way to hypoxia resistance and if treatment with HIF-1 pathway inhibitors may further influence this process.

\section{Acknowledgements of Financial Support}

Work presented in this paper was supported by the National Science Center (Poland) grant 2013/09/N/ NZ1/01873.

\section{REFERENCES}

Achison M, Hupp TR (2003) Hypoxia attenuates the p53 response to cellular damage. Oncogene 22: 3431-3440 doi: 10.1038/sj.onc.1206434

Adams J (2004) The proteasome: a suitable antineoplastic target. Nat Rev Cancer 4: 349-60. doi: 10.1038/nrc1361

Asosingh K, De Raeve H, de Ridder M, Storme GA, Willems A, Van Riet I, Van Camp B, Vanderkerken K (2005) Role of the hypoxic bone marrow microenvironment in 5T2MM murine myeloma tumor progression. Haematologica 90: 810-817

Azab AK, Hu J, Quang P, Azab F, Pitsillides C, Awwad R, Thompson B, Maiso P, Sun JD, Hart CP, Roccaro AM, Sacco A, Ngo HT, Lin CP, Kung AL, Carrasco RD, Vanderkerken K, Ghobrial IM (2012) Hypoxia promotes dissemination of multiple myeloma through acquisition of epithelial to mesenchymal transition-like features. Blood 119: 5782-5794. doi: 10.1182/blood-2011-09-380410

Bianchi G; Ghobrial IM (2014) Biological and clinical implications of clonal heterogeneity and clonal evolution in multiple myeloma. Curr Cancer Ther Rev 10: 70-79. doi: 10.2174/157339471002141124121404

Bolli N, Avet-Loiseau H, Wedge DC, Van Loo P, Alexandrov LB, Martincorena I, Dawson KJ, Iorio F, Nik-Zainal S, Bignell GR,Hinton JW, Li Y, Tubio JM, McLaren S, O' Meara S, Butler AP, Teague JW, Mudie L, Anderson E, Rashid N, Tai YT, Shammas MA, Sperling AS, Fulciniti M, Richardson PG, Parmigiani G, Magrangeas F, Minvielle S, Moreau P, Attal M, Facon T, Futreal PA, Anderson KC, Campbell PJ, Munshi NC (2014) Heterogeneity of genomic evolution and mutational profiles in multiple myeloma. Nat Commun 5: 2997. doi: 10.1038/ncomms3997

Borsi E, Perrone G, Terragna C, Martello M, Dico AF, Solaini G, Baracca A, Sgarbi G, Pasquinelli G, Valente S, Zamagni E, Tacchetti P, Martinelli G, Cavo M (2014) Hypoxia inducible factor-1 alpha as a therapeutic target in multiple myeloma. Oncotarget 5: 1779-1792. doi: 10.18632/oncotarget.1736

Carreau A, El Hafny-Rahbi B, Matejuk A, Grillon C, Kieda C (2011) Why is the partial oxygen pressure of human tissues a crucial parameter? Small molecules and hypoxia. J Cell Mol Med 15: 12391253. doi: 10.1111/j.1582-4934.2011.01258.x.

Chen H, Yan Y, Davidson TL, Shinkai Y, Costa M (2006) Hypoxic stress induces dimethylated histone $\mathrm{H} 3$ lysine 9 through histone 
methyltransferase G9a in mammalian cells. Cancer Res 66: 90099016. doi: 10.1158/0008-5472

Colla S, Storti P, Donofrio G, Todoerti K, Bolzoni M, Lazzaretti M, Abeltino M, Ippolito L, Neri A, Ribatti D, Rizzoli V, Martella E, Giuliani N (2010) Low bone marrow oxygen tension and hypoxia-inducible factor-1alpha overexpression characterize patients with multiple myeloma: role on the transcriptional and proangiogenic profiles of CD138(+) cells. Leukemia 24: 1967-1970. doi: 10.1038/ leu.2010.193

Ebos JM, Lee CR, Cruz-Munoz W, Bjarnason GA, Christensen JG, Kerbel RS (2009) Accelerated metastasis after short-term treatment with a potent inhibitor of tumor angiogenesis. Cancer Cell 15: 232239. doi: 10.1016/j.ccr.2009.01.021

Gewirtz DA (1999) A critical evaluation of the mechanisms of action proposed for the antitumor effects of the anthracycline antibiotics adriamycin and daunorubicin. Biochem Pharmacol 57: 727-741. doi: org/10.1016/S0006-2952(98)00307-4

Giatromanolaki A, Bai M, Margaritis D, Bourantas KL, Koukourakis MI, Sivridis E, Gatter KC (2010) Hypoxia and activated VEGF/ receptor pathway in multiple myeloma. Anticancer Res 30: 2831-2836

Giuliani N, Storti P, Bolzoni M, Palma BD, Bonomini S (2011) Angiogenesis and multiple myeloma. Cancer Microenviron 4: 325-337. doi: 10.1007/s12307-011-0072-9

Graeber TG, Osmanian C, Jacks T, Housman DE, Koch CJ, Lowe SW, Giaccia AJ (1996) Hypoxia-mediated selection of cells with diminished apoptotic potential in solid tumours. Nature 379: 88-91

Granger DN, Kvietys PR (2015) Reperfusion injury and reactive oxygen species: The evolution of a concept. Redox Biology 6: 524-551. doi: $\operatorname{org} / 10.1016 /$ j.redox.2015.08.020

Hammond EM, Asselin MC, Forster D, O'Connor JP, Senra JM, Williams KJ (2014) The meaning, measurement and modification of hypoxia in the laboratory and the clinic. Clin Oncol (R Coll Radiol) 26: 277-288. doi: 10.1016/j.clon.2014.02.002

Harris AL (2002) Hypoxia-a key regulatory factor in tumour growth. Nat Rev Cancer 2: 38-47. doi: 10.1038/nrc704

Harrison JS, Rameshwar P, Chang V, Bandari P (2002) Oxygen saturation in the bone marrow of healthy volunteers. Blood 99: 394

Hideshima T, Richardson P, Chauhan D, Palombella VJ, Elliott PJ, Adams J, Anderson KC (2001) The proteasome inhibitor PS-341 inhibits growth, induces apoptosis, and overcomes drug resistance in human multiple myeloma cells. Cancer Res 61: 3071-3076

Hu J, Van Valckenborgh E, Menu E, De Bruyne E, Vanderkerken K (2012) Understanding the hypoxic niche of multiple myeloma: therapeutic implications and contributions of mouse models. Dis Model Mech 5: 763-771. doi: 10.1242/dmm.008961

Isaacs JS, Jung YJ, Mimnaugh EG, Martinez A, Cuttitta F, Neckers LM (2002) Hsp90 regulates a von Hippel Lindau-independent Hypoxia-inducible factor-1_-degradative pathway. J Biol Chem 277: 29936-29944. doi 10.1074/jbc.M204733200

Jurczyszyn A, Zebzda A, Czepiel J, Perucki W, Bazan-Socha S, Cibor D, Owczarek D, Majka M (2014) Geldanamycin and its derivatives inhibit the growth of myeloma cells and reduce the expression of the MET receptor. J Cancer 5: 480-490. doi: 10.7150/jca.8731

Keats JJ, Chesi M, Egan JB, Garbitt VM, Palmer SE, Braggio E, Van Wier S, Blackburn PR, Baker AS, Dispenzieri A (2012) Clonal competition with alternating dominance in multiple myeloma. Blood 120: 1067-1076. doi: 10.1182/blood-2012-01-405985

Keith B, Simon MC (2007) Hypoxia-inducible factors, stem cells, and cancer. Cell 129: 465-472. doi: 10.1016/j.cell.2007.04.019

Kellner J, Liu B, Kang Y, Li (2013) Fact or fiction-identifying the elusive multiple myeloma stem cell. J Hematol Oncol 6: 91. doi: 10.1186/1756-8722-6-91

Kocemba KA, van Andel H, de Haan-Kramer A, Mahtouk K, Versteeg R, Kersten MJ, Spaargaren M, Pals ST (2013) The hypoxia target adrenomedullin is aberrantly expressed in multiple myeloma and promotes angiogenesis. Leukemia 27: 1729-1737. doi: 10.1038/ leu.2013.76

Koh MY, Powis G (2012) Passing the baton: the HIF switch. Trends Biochem Sci 37: 364-372. doi.org/10.1016/j.tibs.2012.06.004

Lévesque JP, Winkler IG. (2011) Hierarchy of immature hematopoietic cells related to blood flow and niche. Curr Opin Hematol 18: 220 225. doi: 10.1097/MOH.0b013e3283475fe7

Lévesque JP, Winkler IG, Hendy J, Williams B, Helwani F, Barbier V, Nowlan B, Nilsson SK (2007) Hematopoietic progenitor cell mobilization results in hypoxia with increased hypoxia-inducible transcription factor-1 alpha and vascular endothelial growth factor A in bone marrow. Stem Cells 25: 1954-1965. doi: 10.1634/stemcells.2006-0688

Li Z, Rich JN (2010) Hypoxia and hypoxia inducible factors in cancer stem cell maintenance. Curr Top Microbiol Immunol 345: 21-30. doi: 10.1007/82_2010_75

Liou GY, Storz P (2010) Reactive oxygen species in cancer. Free Radic Res 44: 479-496. doi:10.3109/10715761003667554

Loges S, Mazzone M, Hohensinner P, Carmeliet P (2009) Silencing or fueling metastasis with VEGF inhibitors: antiangiogenesis revisited. Cancer Cell 15: 167-170. doi: 10.1016/j.ccr.2009.02.007
Lohr JG, Stojanov P, Carter SL, Cruz-Gordillo P, Lawrence MS, Auclair D, Sougnez C, Knoechel B, Gould J, Saksena G, Cibulskis K, McKenna A, Chapman MA, Straussman R, Levy J, Perkins LM, Keats JJ, Schumacher SE, Rosenberg M (2014) Widespread genetic heterogeneity in multiple myeloma: implications for targeted therapy. Cancer Cell 25: 91-101. doi: 10.1016/j.ccr.2013

Lu L, Payvandi F, Wu L, Zhang LH, Hariri RJ, Man HW, Chen RS, Muller GW, Hughes CC, Stirling DI, Schafer PH, Bartlett JB (2009) The anti-cancer drug lenalidomide inhibits angiogenesis and metastasis via multiple inhibitory effects on endothelial cell function in normoxic and hypoxic conditions. Microvasc Res 77: 78-86. doi: 10.1016/j.mvr.2008.08.003

Lu Y, Chu A, Turker MS, Glazer PM (2011) Hypoxia-induced epigenetic regulation and silencing of the BRCA1 promoter. Mol Cell Biol 31: 3339-3350. doi: 10.1128/MCB.01121-10

Martin SK, Diamond P, Williams SA, To LB, Peet DJ, Fujii N, Gronthos S, Harris AL, Zannettino AC (2010) Hypoxia-inducible factor-2 is a novel regulator of aberrant CXCL12 expression in multiple myeloma plasma cells. Haematologica 95: 776-784. doi: 10.3324/ haematol.2009.015628

McIntyre A, Harris AL (2015) Metabolic and hypoxic adaptation to anti-angiogenic therapy: a target for induced essentiality. EMBO Mol Med 7: 368-379. doi: 10.15252/emmm.201404271

Melchor L, Brioli A, Wardell CP, Murison A, Potter NE, Kaiser MF, Fryer RA, Johnson DC, Begum DB, Hulkki Wilson S, Vijayaraghavan G, Titley I, Cavo M, Davies FE, Walker BA, Morgan GJ (2014) Single-cell genetic analysis reveals the composition of initiating clones and phylogenetic patterns of branching and parallel evolution in myeloma. Leukemia 28: 1705-1715. doi: 10.1038/ leu. 2014.13

Minchenko O, Opentanova I, Minchenko D, Ogura T, Esumi H (2004) Hypoxia induces transcription of 6-phosphofructo-2-kinase/fructose-2,6-biphosphatase-4 gene via hypoxia-inducible factor-1alpha activation. FEBS Lett 576: 14 -20. doi: 10.1016/j.febslet.2004.08.053

Mitra AK, Mukherjee UK, Harding T, Jang JS, Stessman H, Li Y, Abyzov A, Jen J, Kumar S, Rajkumar V, Van Ness B. (2014) Single-cell transcriptomics identifies intra-tumor heterogeneity in human myeloma cell lines. Blood 124: 3385

Mitsiades CS, Mitsiades NS, McMullan CJ, Poulaki V, Kung AL, Davies FE, Morgan G, Akiyama M, Shringarpure R, Munshi NC, Richardson PG, Hideshima T, Chauhan D, Gu X, Bailey C, Joseph M, Libermann TA, Rosen NS, Anderson KC (2006) Antimyeloma activity of heat shock protein-90 inhibition. Blood 107: 1092-1100. doi: 10.1182/blood-2005-03-1158

Muz B, de la Puente P, Azab F, Luderer M, Azab AK (2014) Hypoxia promotes stem cell-like phenotype in multiple myeloma cells. Blood Cancer J 4: 262. doi: 10.1038/bcj.2014.82

Mysore VS, Szablowski J, Dervan PB, Frost PJ (2016) A DNA-binding molecule targeting the adaptive hypoxic response in multiple myeloma has potent antitumor activity. Mol Cancer Res 14: 253-266. doi: 10.1158/1541-7786.MCR-15-0361

Newman B, Liu Y, Lee HF, Sun D, Wang Y (2012) HSP90 inhibitor 17-AAG selectively eradicates lymphoma stem cells. Cancer Res 72: 4551-4561. doi: 10.1158/0008-5472.CAN-11-3600

Obeng EA, Carlson LM, Gutman DM, Harrington WJ Jr, Lee KP, Boise LH (2006) Proteasome inhibitors induce a terminal unfolded protein response in multiple myeloma cells. Blood 107: 4907-4916. doi: 10.1182/blood-2005-08-3531

Palumbo A, Gay F, Bringhen S, Falcone A, Pescosta N, Callea V, Caravita T, Morabito F, Magarotto V, Ruggeri M, Avonto I, Musto P, Cascavilla N, Bruno B, Boccadoro M (2008) Bortezomib, doxorubicin and dexamethasone in advanced multiple myeloma. Ann Oncol 19: 1160-1165 doi: $10.1093 /$ annonc/mdn018

Pàez-Ribes M, Allen E, Hudock J, Takeda T, Okuyama H, Viñals F, Inoue M, Bergers G, Hanahan D, Casanovas O. (2009) Antiangiogenic therapy elicits malignant progression of tumors to increased local invasion and distant metastasis. Cancer Cell 15: 220-231. doi: 10.1016/j.ccr.2009.01.027

Papandreou I, Krishna C, Kaper F,Cai D, Giaccia AJ, Denko NC (2005) Anoxia is necessary for tumor cell toxicity caused by a low-oxygen environment. Cancer Res 65: 3171-3178. doi: 10.1158/0008-5472.CAN-04-3395

Papandreou I, Lim AL, Laderoute K, Denko NC (2008) Hypoxia signals autophagy in tumor cells via AMPK activity, independent of HIF-1, BNIP3, and BNIP3L. Cell Death Differ 15: 1572-1581. doi: 10.1038/cdd.2008.84

Parmar K, Mauch P, Vergilio JA, Sackstein R, Down JD. (2007) Distribution of hematopoietic stem cells in the bone marrow according to regional hypoxia. Proc Natl Acad Sci USA 104: 5431-5436. doi: $10.1073 /$ pnas.0701152104

Rohwer N, Cramer T (2011) Hypoxia-mediated drug resistance: novel insights on the functional interaction of HIFs and cell death pathways. Drug Resist Updat 14: 191-201. doi: 10.1016/j.drup.2011.03.001

Rzymski T, Milani M, Pike L,Buffa F,Mellor HR,Winchester L,Pires I,Hammond E, Ragoussis I, Harris AL (2010) Regulation of au- 
tophagy by ATF4 in response to severe hypoxia. Oncogene 29: 4424 4435. doi: $10.1038 /$ onc. 2010.191

Semenza GL (2002) HIF-1 and tumor progression: pathophysiology and therapeutics. Trends Mol Med 8: 62-67

Semenza GL (2003) Targeting HIF-1 for cancer therapy. Nat Rev Cancer 3: 721-732. doi: $10.1038 /$ nrc1187

Semenza GL (2007) Hypoxia-inducible factor 1 (HIF-1) pathway. Sci STKE 407. doi: $10.1126 /$ stke. $4072007 \mathrm{~cm} 8$

Shahrzad S, Bertrand K, Minhas K, Coomber BL (2007) Induction of DNA hypomethylation by tumor hypoxia. Epigenetics 2: 119-125

Shin DH, Chun YS, Lee DS, Huang LE, Park JW. (2008) Bortezomib inhibits tumor adaptation to hypoxia by stimulating the FIH-mediated repression of hypoxia-inducible factor-1. Blood 111: 3131-3136. doi: 10.1182/blood-2007-11-120576

Thienpont B, Steinbacher J, Zhao H, D'Anna F, Kuchnio A, Ploumakis A, Ghesquière B, Van Dyck L, Boeckx B, Schoonjans L, Hermans E, Amant F, Kristensen VN, Peng Koh K, Mazzone M, Coleman M, Carell T, Carmeliet P, Lambrechts D (2016) Tumour hypoxia causes DNA hypermethylation by reducing TET activity. Nature 537: 63-68. doi: 10.1038/nature19081

Tsai YP, WU KJ, (2014) Epigenetic regulation of hypoxia-responsive gene expression: focusing on chromatin and DNA modifications. Int J Cancer 134: 249-256. doi: 10.1002/ijc.28190

Turilova VI, Smirnova TD (2012) Karyotypic variability of human Multiple Myeloma cell lines. Cell and Tissue Biology 6: 442-457. doi: 10.1134/S1990519X12050136

Vasudev NS, Reynolds AR. (2014) Anti-angiogenic therapy for cancer: current progress, unresolved questions and future directions. Angiogenesis 17: 471-494. doi: 10.1007/s10456-014-9420-y
Vaupel P (2004) The role of hypoxia-induced factors in tumor progression. Oncologist 9: 10-7. doi: 10.1634/theoncologist.9-90005-10

Watson JA, Watson CJ, McCann A, Baugh J (2010) Epigenetics, the epicenter of the hypoxic response. Epigenetics 5: 293-296

Weinmann M, Jendrossek V, Güner D, Goecke B, Belka C (2004) Cyclic exposure to hypoxia and reoxygenation selects for tumor cells with defects in mitochondrial apoptotic pathways. Faseb J 18: 19061908. doi: 10.1096/fj.04-1918fje

Wu D, Yotnda P (2011) Induction and testing of hypoxia in cell culture. J Vis Exp 12: 2899. doi: 10.3791/2899

Xia Y, Choi HK, Lee K. (2012) Recent advances in hypoxia-inducible factor (HIF)-1 inhibitors. Eur J Med Chem 49: 24-40. doi: 10.1016/j. ejmech.2012.01.033

Zhang J, Sattler M, Tonon G, Grabher C, Lababidi S, Zimmerhackl A, Raab MS, Vallet S, Zhou Y, Cartron MA (2009) Targeting angiogenesis via a c-Myc/hypoxia-inducible factor-1alpha-dependent pathway in multiple myeloma. Cancer Res 69: 5082-5090. doi: 10.1158/0008-5472.CAN-08-4603

Zhao T, Zhu Y, Morinibu A, Kobayashi M, Shinomiya K, Itasaka S, Yoshimura M, Guo G, Hiraoka M, Harada H (2014) HIF-1-mediated metabolic reprogramming reduces ROS levels and facilitates the metastatic colonization of cancers in lungs. Sci Rep 4: 3793. doi: $10.1038 /$ srep03793

Zlei M, Egert S, Wider D, Ihorst G, Wäsch R, Engelhardt M (2007) Characterization of in vitro growth of multiple myeloma cells. Exp Hematol 35: 1550-1561. doi: 10.3791/2899 